\title{
Caminhos percorridos por transexuais: em busca pela transição de gênero
}

\author{
Paths taken by transsexuals: in search for gender transition
}

Otto Felipe Dias Hanauer ${ }^{\mathbf{1}}$, Ana Paula Azevedo Hemmi $\mathbf{1}$

DOI: $10.1590 / 0103-110420195807$

RESUMO Este estudo teve como objetivo descrever os caminhos percorridos por transexuais, visando conhecer seus itinerários na busca por atendimento às suas necessidades e demandas em saúde. Como percurso metodológico, realizou-se um estudo exploratório com abordagem qualitativa, tendo por referência teórica os Itinerários Terapêuticos (IT). Foram realizadas entrevistas com sete transexuais. A partir dessas, foi possível identificar alguns marcos nos IT dos(as) entrevistados(as), tais como o 'reconhecimento como trans' e a 'rede de cuidados em saúde: em busca da modificação corporal'. Acredita-se que este estudo permitiu dar visibilidade à trajetória de pessoas transexuais, considerando suas vivências, seus conflitos e dificuldades para conseguirem alcançar sua identidade de gênero. Além disso, foi possível perceber como a transexualidade é, ainda, uma condição não vista por profissionais de saúde e gestores da Rede de Atenção à Saúde, como também por parte de pessoas do convívio social. Isso sinaliza para a importância deste estudo em pelo menos três aspectos: social, político e de saúde.

PALAVRAS-CHAVE Pessoas transgênero. Assistência integral à saúde. Minorias sexuais e de gênero. Sistema Único de Saúde. Terapêutica.

ABSTRACT This study aimed to describe the paths taken by transsexuals, aiming to know their itineraries in the search for meeting their health needs and demands. As a methodological choice, an exploratory study with a qualitative approach was carried out, using Therapeutic Itineraries (IT) as a theoretical reference. Interviews were conducted with seven transsexuals. From those, it was possible to identify some milestones in the IT of the interviewees, such as the 'recognition as a trans' and the 'health care network: in search for body modification'. It is believed that this study allowed to give visibility to the trajectory of transsexual people, considering their experiences, their conflicts, and their difficulties to achieve gender identity. In addition, it was possible to perceive how transsexuality is still a condition disregarded by health professionals and managers of the Health Care Network, as well as by a share of the people of social life. This points to the importance of this study in at least three aspects: social, political, and regarding health.

KEYWORDS Transgender persons. Comprehensive health care. Sexual and gender minorities. Unified Health System. Therapeutics.

1 Universidade Federal dos Vales do Jequitinhonha e Mucuri (UFVJM) Diamantina (MG), Brasil. ottohanauer@gmail.com 


\section{Introdução}

A transexualidade pode ser entendida como a condição do indivíduo cuja identidade de gênero difere daquela designada no nascimento. O termo transexual é utilizado para nos referirmos a homens e a mulheres trans, na tentativa de designá-los como pessoas que não se identificam com as atribuições socioculturais de masculino e feminino. Em alguns casos, podem, por meio de modificações corporais, exercer sua identidade de gênero de acordo com seu bem-estar biopsicossocial1.

O Brasil pode ser considerado um país que, por meio do Sistema Único de Saúde (SUS), está na vanguarda da garantia de direitos e de reconhecimento de gênero. Desde 2008, o Processo Transexualizador (PT) foi instituído pelo Ministério da Saúde (MS) visando ao atendimento de pessoas que sofrem com a incompatibilidade de gênero. O PT, no âmbito do SUS, pode ser definido como um conjunto de estratégias assistenciais para os(as) 'trans' que pretendem realizar modificações corporais, incluindo as cirurgias de transgenitalização e a hormonioterapia por exemplo. Dessa forma, o sistema de saúde brasileiro busca assegurar uma cobertura gratuita de saúde e, também, a integralidade no atendimento aos(às) transexuais ${ }^{2}$.

No entanto, a despeito das críticas acadêmicas e do movimento mundial em prol da despatologização das identidades trans, é possível perceber, no contexto brasileiro, uma interpretação da transexualidade que a associa a uma patologia ${ }^{3}$. Esta tem sido vista como um transtorno psiquiátrico e acaba por orientar políticas públicas e programas destinados a esse segmento da população.

Além disso, é possível perceber que, apesar de o PT estar regulamentado por uma série de portarias, ainda há poucos serviços preparados para atender às demandas de transexuais. No Brasil, existem nove serviços habilitados para o PT. Desses, cinco realizam atendimento ambulatorial e hospitalar, enquanto os demais oferecem somente serviços ambulatoriais. Em
Minas Gerais, por exemplo, há somente um serviço habilitado pelo MS, para realização do PT, que se destina exclusivamente ao atendimento ambulatorial' 1 . Isso significa que aquelas pessoas que almejam a redesignação sexual, por meio de cirurgias, contando com o SUS, encontrarão alguns obstáculos.

Somado a isso, os(as) transexuais, geralmente, encontram-se mais distanciados(as) dos serviços de saúde. Isso ocorre, especialmente, por falta de mecanismos específicos, como ações de promoção à saúde que facilitem o acesso dessa população a tais serviços, a fim de que possam tratar adequadamente de sua saúde ${ }^{4}$.

Diante disso, este estudo teve como objetivo descrever os caminhos percorridos por transexuais, visando conhecer seus itinerários na busca por atendimento às suas necessidades e demandas de saúde. Partimos do pressuposto de que as pessoas transexuais apresentam diversas necessidades em relação a seu processo de redesignação sexual, porém, devido às limitações dos serviços de saúde, buscam possibilidades distintas e informais para atenderem às suas demandas.

Segundo Bento ${ }^{5}$, as pessoas apresentam diferentes demandas em saúde em cada tempo, sendo importante perceber que, no caso de transexuais, o processo de redesignação sexual pode ou não solucionar seus problemas existenciais. Isso se deve, em grande parte, pelo fato de vivermos em uma sociedade sexista, racista, xenofóbica ehomofóbica, e, portanto, possuidora de dificuldades para compreender o diferente ${ }^{5,6}$.

\section{Métodos}

Trata-se de um estudo exploratório com abordagem qualitativa, tendo por referência teórica os Itinerários Terapêuticos (IT). A combinação entre abordagem qualitativa e IT permite que o pesquisador possa compreender os percursos traçados pelos indivíduos em busca de ajuda para reestabelecer sua saúde ${ }^{7}$, a partir de uma interação direta com os sujeitos pesquisados. Ou seja, é possível obter dados descritivos, 
sobre as pessoas e suas vivências, com base nos processos interativos entre o pesquisador e seu objeto de estudo ${ }^{8}$. Assim, assume-se, neste estudo, que o itinerário individual não é predeterminado, mas se norteia por uma experiência social e coletiva compartilhada em diferentes cenários da vida cotidiana ${ }^{9}$.

A pesquisa foi realizada em um município do interior do estado de Minas Gerais de aproximadamente 45 mil habitantes, com forte tradição católica e economia fortemente incentivada pelo turismo, além de referência de saúde, administrativa e assistencial, de 33 munícipios do Vale do Jequitinhonha. Vinte e um(a) transexuais foram identificados(as) no município em questão, tanto por meio dos cadastros existentes nos serviços de saúde quanto por inserção de um dos pesquisadores em um grupo composto por acadêmicos da Instituição de Ensino Superior, que realiza diversos debates sobre as questões envolvendo Lésbicas, Gays, Bissexuais, Travestis e Transexuais (LGBT).

Para a coleta de dados, ocorrida no período de maio a junho de 2018, consideraram-se pessoas maiores de 18 anos, tendo em vista ser a idade mínima autorizada pelo MS para o início do atendimento clínico e da hormonioterapia no $\mathrm{SUS}^{10}$, além de pessoas que se autodeclararam transexuais e que residiam nesse município no momento da pesquisa.

À medida que as entrevistas iam sendo realizadas, as pessoas eram solicitadas a indicar possíveis sujeitos participantes. Essa estratégia, também conhecida como bola-de-neve, é frequentemente utilizada em pesquisas que lidam com grupos sociais, dos quais não se tem um levantamento estatístico ou envolvem alguma situação mais delicada"1 . Geralmente, as pessoas entrevistadas indicavam outras, porém, duas das que foram indicadas eram menores de idade e, por isso, não poderiam ser entrevistadas. Ademais, uma ainda não se afirmava como transexual, então, optamos por respeitar sua posição em não participar da pesquisa. As demais pessoas não quiseram participar do estudo e/ou haviam se mudado da cidade no momento da coleta dos dados.

Esses aspectos contribuíram para que fossem entrevistados somente sete transexuais. As entrevistas foram realizadas em local de escolha dos(as) entrevistados(as) e seguiram um roteiro semiestruturado de forma a dar liberdade às vivências individuais. Estas foram gravadas e realizadas após a leitura, explicação da pesquisa e assinatura do Termo de Consentimento Livre e Esclarecido (TCLE), conforme a Resolução no 466/2012, do Conselho Nacional de Saúde ${ }^{12}$. Tanto a pesquisa quanto o TCLE foram aprovados pelo Comitê de Ética em Pesquisa da Universidade Federal dos Vales do Jequitinhonha e Mucuri, por meio do parecer de número 2.635.140.

As entrevistas transcritas foram organizadas com auxílio do software NVivo e analisadas por meio de análise de conteúdo, buscando-se resgatar a densidade dos relatos e trazendo recortes importantes que pudessem ilustrar o processo de transexualização ${ }^{13}$. Além disso, os significados das situações vivenciadas e o seu contexto social, cultural e político também foram considerados no momento da análise dos dados.

As categorias foram construídas a partir das diferentes trajetórias apresentadas pelas pessoas entrevistadas que apontaram aspectos relacionados com a identificação como transexual e quanto à influência das redes sociais nesse processo, bem como da transição e sua relação com os serviços de saúde. Como tais aspectos falam do percurso traçado pelas pessoas entrevistadas e, simultaneamente, encontram-se imbricados, foram organizadas as seguintes categorias: reconhecimento como trans e a rede de cuidados em saúde: em busca da modificação corporal.

No intuito de preservar a identidade daqueles(as) que aceitaram colaborar para a pesquisa, todas as pessoas serão referenciadas neste estudo por meio do uso do nome de flores, tais como: Jasmim, Magnólia, Narciso, Lírio, Cravo, Hibisco, Sempre-viva. 
Quadro 1. Perfil dos(das) entrevistados(as)

\begin{tabular}{|c|c|c|c|c|c|c|c|}
\hline & Jasmim & Magnólia & Narciso & Lírio & Cravo & Hibisco & Sempre-viva \\
\hline Idade & $\star$ & 51 & 21 & 23 & 24 & 20 & 29 \\
\hline Trans & Mulher & Mulher & Homem & Homem & Homem & Homem & Mulher \\
\hline Profissão & Cabelereira & Prostituta & Desempregado & Desempregado & Pintor & Estudante & Estudante \\
\hline
\end{tabular}

Fonte: Elaboração própria, 2018

*Não quis revelar sua idade.

\section{Resultados e discussão}

\section{O reconhecimento como trans}

O processo de autoidentificação se mostra como importante e decisivo na vida das pessoas entrevistadas. Trata-se de um marco que descreve a descoberta do não pertencimento à identidade de gênero conforme designada em seu nascimento. Essa fase é marcada, principalmente, pelo estranhamento do próprio corpo físico. Com alguns(algumas) dos(as) transexuais entrevistados(as), tal estranhamento se manifestou na infância, ao perceberem uma não correspondência entre o corpo biológico e o sentir-se homem ou mulher.

Hibisco relata que se considerava uma criança normal, embora percebesse algo diferente e que não se encaixava em um padrão. Sentia-se "um menino que pensava como menina". Sempre-viva, por sua vez, recorda-se de um momento, aos seus quatro anos de idade, em que se encontrava brincando com os primos e sentiu um desejo de cortar o pênis. Segundo informa, não gostava de ficar com "aquilo entre as pernas", pois, para ela: "sou trans desde que eu nasci”. Cravo, Jasmim, Lírio e Narciso também relatam que, desde crianças, sentiam certo estranhamento com o corpo e com as normas sociais impostas de comportamento para homens e mulheres. Conforme pode ser visto nos seguintes relatos:

Ah, eu nunca me vi homem. Nunca me vi de barba! Nunca me vi 'coçando o saco'. Essas coisas horríveis, sabe?! Eu nunca me encaixei nisso.
Então, eu sempre me vi mulher! (Jasmim, 2018).

Nunca (es)tava encaixada no meio das meninas, sabe, na escola, em brincadeira, em nada. Então, era sempre diferente pra mim, eu ficava pensando: por que isso? Eu me sentia um menino normal. Brincava sempre com os meninos e, desde criança, eu odiava pôr vestido e chorava mesmo. Eu não queria pôr brinco, prender o cabelo, eu sempre gostava só de ficar de bermuda e chinelo, brincando de bola na rua. (Lírio, 2018).

Eu queria ter uma barba, sempre vestia as roupas do meu padrasto, essas coisas assim. Eu sempre me vesti assim, com traços mais masculinos, essas coisas. Mas, quando eu adaptei mesmo a roupa do masculino [foi] depois dos meus 15 anos, que eu cortei cabelo e comecei a usar essas coisas todas [...]. (Narciso, 2018).

A partir da experiência relatada por eles(as), a identificação como transexual não se manifesta, necessariamente, na infância, já que depende do processo de cada indivíduo. Sempre-viva afirma que, aos 22 anos, começou a se vestir de mulher escondida em casa. Jasmim relata que começou com "um batom, uma sombra, um brinco [...], fui me encaixando e, depois, eu surgi".

Na construção social de gênero, instituições como a família tornam-se uma peça fundamental para moldar os comportamentos das crianças, conforme o que é aceito ou não pela sociedade, reforçando assim padrões de comportamento heteronormativos e cisnormativos.

A cisnormatividade é um conceito que denota a norma que legitima como saudáveis, 
naturais e verdadeiras apenas as pessoas que se identificam com o sexo que lhes foi designado ao nascimento, sempre assumindo a binariedade homem/mulher ${ }^{14}$. A heteronormatividade, por sua vez, busca relacionar a heterossexualidade como norma regulatória, seja entre as relações afetivas ou comportamentos em uma dada sociedade ${ }^{15}$.

Essas normas regulam o que é tido como normal em questões de gênero e sexo, impondo maneiras de ser, de agir, de se comportar e, por conseguinte, trazendo consequências diversas à vida das pessoas trans. Segundo Butler' ${ }^{16}$, gênero é uma construção social, em que nós aprendemos a ser homem ou mulher em um contexto sociocultural, cuja norma é a heterossexualidade (e a cisnormatividade); e qualquer um(a) que fuja dessa norma é, naturalmente, excluído(a) ${ }^{\mathbf{1 6}}$.

O sistema binário de gênero, que distingue os padrões de masculino e feminino, pode ser interpretado por aqueles(as) que não se identificam com o gênero do nascimento como um aspecto conflituoso, podendo se expressar como uma forma de violência, já que a sociedade impõe regras sobre as normas de gênero ${ }^{5,17}$.

A transexualidade pode ser revelada como uma patologia, já que possibilita uma outra forma de enunciação de expressão do sujeito. Isso pode ser entendido como uma anormalidade, uma vez que não se encaixam em um modelo de corpo binário, fazendo com que sofram diversos tipos de exclusão"1. É assim que podemos pensar nas possíveis formas de violência, já que o sexismo e a homofobia emergem como consequência do regime binário da sexualidade $^{6}$. A homofobia, sendo uma forma do (cis)sexismo, "rejeita, igualmente, todos aqueles que não se conformam com o papel predeterminado para seu sexo biológico"6(34). Pode-se concluir, então, que o (cis)sexismo é responsável pela produção de violência e invisibilidade sobre as pessoas trans, o que também pode ser chamado de transfobia ${ }^{\mathbf{1 4}}$.

Como exemplo, podemos apontar as experiências das pessoas entrevistadas que revelam um processo de identificação permeado de conflito consigo próprio(a) e com as pessoas próximas, como familiares e amigos, pois sentem-se não compreendidos(as) de diversas formas. Segundo Magnólia, sempre sofreu discriminação, tanto por parte da família quanto do contexto em que vivia. Hibisco, aos 20 anos de idade, também teve de lidar com agressões físicas e verbais advindas do pai e de garotos da vizinhança. Segundo informa, chegou em um determinando momento em que a família "teve que aceitar", pois sentia que não era justo ele(a) ter que prescindir de "viver a vida" para ser do jeito que a família impunha. Hibisco, então, afirma: "é a mesma coisa de prender um passarinho dentro de uma gaiola e não deixar ele voar [...] tirar ele da liberdade dele".

A despeito da falta de apoio familiar ou de pessoas próximas, na medida em que o tempo vai passando e vão se familiarizando com casos semelhantes aos seus, as pessoas parecem conseguir se autoperceber com aquele gênero com o qual se identificam. Nesse aspecto, a importância das redes sociais é fundamental.

Hibisco relata que, na adolescência, conheceu o que era a transexualidade quando assistiu a uma reportagem na televisão sobre a Roberta Close. No grupo do Facebook ${ }^{\circledR}$, além de conhecer acerca do PT, descobriu como outras meninas trans viveram, e se descobriram, causando uma sensação de pertencimento e conforto na identificação como transexual.

No processo de identificação, parece ter havido para alguns(algumas), em um primeiro momento, uma relação da transexualidade com a homossexualidade e como patologia, conforme o caso de Magnólia. Segundo ela, somente quando se mudou de cidade, durante a adolescência, começou a se assumir. A mãe a levou ao médico, pois pensara que o filho estivesse doente, e lá, fora diagnosticado como gay.

Cravo e Lírio também afirmam que se identificavam como lésbicas. "De princípio, a gente se identifica como lésbica, né?” (Cravo, 2018). Cravo relata que tal identificação durou até os seus 20 anos, quando ele conheceu o termo transexual. Lírio afirma que, na adolescência, sabia que "tava faltando algo, não é só roupa, não é só cabelo [...]”. Ele relata que 
este momento de identificação foi um alívio em sua vida:

Eu comecei a me identificar com essas pessoas, com o que a gente conversava e, quando eu conheci as pessoas, tipo assim, foi muito... eu falei assim: nossa, é isso que eu sou, entendeu? Foi, tipo assim, um alívio. [Vo]cê tá carregando uma coisa nas suas costas e [vo]cê fica assim: me descobri! Entende? (Lírio, 2018).

Dentre as narrativas de pessoas transexuais, é comum se observar a expressão "segunda saída do armário”15(99), que significa que a homossexualidade, já conhecida pela sociedade, é uma primeira aproximação à transexualidade. Porém, quando percebem que os códigos culturais da homossexualidade não conseguem mais nomear a transição vivenciada, o incômodo em relação à identidade de gênero vem à tona; e, então, percebem que não se trata apenas de um desejo sexual15.

Quando se identificam e começam a se compreender, o conflito extrapola do corpo para o nome de registro. Dessa forma, a identificação passa a se refletir no uso de um nome social, uma vez que este se configura como uma reafirmação do próprio eu. A necessidade de ter o nome social registrado é algo que se relaciona não somente à identidade de gênero, mas também como uma forma de evitar constrangimentos. Jasmim afirma que, durante anos, sempre apresentava o documento original e algum documento que possuísse o nome social, solicitando que a pessoa a chamasse pelo último. As pessoas, "por respeito ou por medo", a chamavam, então, pelo nome social.

No caso de Hibisco, ele(a) ainda não impõe seu nome social aos familiares e amigos, uma vez que acredita ser necessário transformar-se corporalmente para, então, dar início ao processo de mudança do nome.

Tipo assim, enquanto eu tiver de menino, eu prefiro estar com nome de registro. Aí, quando for mais pra frente, quando eu for mudando, aí vou mudar meus documentos. Aí, eu vou preferir que me chamem pelo meu nome que esta(rá) nos meus documentos, que vai ser Luma. (Hibisco, 2018).

O nome de registro possui um peso importante para as pessoas transexuais, e algumas delas almejam sua alteração. Além de algumas pessoas demandarem por mudanças corporais, a mudança do nome nas instâncias judiciais é uma reivindicação frequente pela população transexual. Porém, apesar do Provimento do Conselho Nacional de Justiça ${ }^{\circ} 73 / 2018$ autorizar a retificação de registro civil de homens e mulheres transexuais pelos cartórios de registro civil, não demandando mais processos judiciais ${ }^{18}$, não podemos deixar de destacar que o percurso ainda é longo, pois ainda há a aceitação da sociedade. A disparidade entre o nome de registro civil e a aparência física é motivo de discriminação que pode levar ao isolamento social, ao desemprego e ao distanciamento dos serviços de saúde. Nesse sentido, a possibilidade de alteração do nome antes da cirurgia de readequação da genitália, ou mesmo sem a realização desta, é um grande avanço para a promoção da saúde integral da pessoa trans ${ }^{19}$.

No entanto, mesmo com as dificuldades de reconhecimento pela sociedade, os(as) entrevistados(as) perseguem trajetórias em busca do seu processo de transição de gênero. Esse processo pode ser entendido como uma forma de equilibrar a identidade trans com o corpo físico; e é nesse momento que as redes de cuidados em saúde se fazem presentes.

\section{As redes de cuidados em saúde: em busca da modificação corporal}

A presença das redes de cuidados em saúde foi percebida como algo central que permeia a vida das pessoas transexuais. Os elementos que as compõem se relacionam tanto com aqueles que envolvem a família, amigos e relacionamentos interpessoais como também por todo conteúdo midiático, proporcionado, principalmente, pela televisão e pela internet. São também perpassadas pelos diferentes serviços 
de saúde e/ou instituições. O processo de identificar-se como transexual, assim como a adoção de medidas que possam tomar em relação às modificações corporais, está intimamente relacionado com a presença ou não dessas redes.

As redes possuem um significado, que sugere para as pessoas transexuais ora um apoio a sua condição, ora rejeição. $\mathrm{O}$ aspecto da rejeição pôde ser compreendido como uma forma de expressão dos valores da sociedade em relação às pessoas transexuais, já que ainda há muito desconhecimento, julgamentos e discriminação ante as questões de identidade de gênero ${ }^{\mathbf{1 5 , 2 0 - 2 2}}$.

Magnólia, pertencendo a uma família religiosa, relata ter vivido muita repressão familiar. Segundo informa, as pessoas na sociedade e da sua família "não tinha(m) muito entendimento", e, portanto, não entendiam a sua condição.

Como muitos(as) transexuais não podem contar com familiares e amigos, as redes sociais se tornam uma possibilidade de "busca solitária de respostas"23(18). Geralmente, tais respostas representam uma forma de libertação às dúvidas relacionadas com a identidade de gênero, principalmente quando se deparam com sujeitos que compartilham os momentos difíceis já vivenciado por eles(as). Dessa forma, a internet aparece nos discursos como um importante meio de socialização e como uma forma de obtenção de informações acerca das modificações corporais, realizadas pelos serviços de saúde disponibilizados pelo SUS ou não, assim como no uso de medicamentos ${ }^{\mathbf{1 2}}$.

Hibisco afirma que criou um 'bloqueio' em seu ambiente familiar e em todo seu contexto social; e somente com ajuda de um grupo intitulado Terapia Hormonal para Transexuais, do Facebook ${ }^{\circledR}$, conseguiu superar seu trauma. Conforme relata, esse grupo possibilitou obter informações e, logo, compreender seu próprio processo. Além desse grupo, Hibisco afirma ainda que: "nunca tive alguém assim aberto pra conversar. É a primeira vez que eu converso sobre isso", referindo-se ao contato com os pesquisadores da presente pesquisa. Para Narciso, Cravo e Lírio, os grupos do Facebook ${ }^{\circledast}$ e do WhatsApp ${ }^{\circledR}$ também foram cruciais para conhecerem sobre modificações corporais. A partir desses grupos, receberam diversas orientações sobre a busca por profissionais, hormônios e informações sobre os procedimentos de modificação corporal.

[...] que hoje tem a rede social. Então, [vo]cê conhece o mundo todo, as pessoas, tudo. Porque têm os grupos de fora, dos Estados Unidos, tem o grupo de gente lá de São Paulo... tem grupo de várias regiões do mundo. Tudo no Face. E por ser bom de [vo]cê compartilhar informações sobre hormônio, [...] vê quem que é famoso que toma, famoso que não toma. Essas coisas, sabe? Então, hoje é muito fácil. (Cravo, 2018).

Além do Facebook ${ }^{\circledR}$, a televisão e os sites da internet também são formas de buscarem apoio e informações sobre quaisquer dúvidas. Sempre-Viva - que também afirma não possuir amigos com quem conversar, nem ter apoio dos serviços de saúde - revela:

eu lia na internet, né? No doutor [Google] de muita gente hoje, pra nós principalmente, porque as pessoas [dos serviços de saúde] não sabem atender a gente.

Lírio, aos seus 19 anos, assistiu uma entrevista com João Nery em um programa de televisão - escritor e ativista político considerado o primeiro homem transexual do Brasil a ter sido operado na década de 1970. Isso o incentivou a buscar mais informações sobre transexuais, conhecendo diversas pessoas que o auxiliaram no processo de transição pelo SUS.

Esse processo tende a ser menos difícil para as pessoas trans, quando elas experimentam uma "boa passabilidade social" que é entendida como a "capacidade de se fazer vista ou visto, de acordo com a identidade de gênero com a qual se identifica"24(131); algo que os(as) levam a uma maior aceitação social. Por outro lado, há pessoas trans que não são tão passáveis 
socialmente, o que pode dificultar as relações com aqueles que não aceitam sua identidade.

A busca pela passabilidade pode estar relacionada com um sentimento de urgência em modificar o corpo. Nesse caso, o uso de hormônios é uma das primeiras providências para essa modificação corporal, seja com ou sem acompanhamento médico. O hormônio se torna, então, um

agente social e político, que inventa possibilidades de humanidade, ao instaurar tecnologias de gênero particulares, nesse processo de cuidado em saúde25(2).

Os autores apontam que tecnologias de gênero se referem às tecnologias médicas, incluindo as cirurgias e as intervenções farmacológicas e/ou químicas.

Magnólia destaca o uso de hormônios como o início de uma nova vida, pois deixou uma pessoa do sexo masculino para trás, a fim de transformar-se em uma outra pessoa, sentindo-se em um corpo mais feminizado.

O primeiro [passo] foi tomar anticoncepcional né, o hormônio feminino. A primeira coisa que [usei], quando eu iniciei pra vida, foi o hormônio feminino. (Magnólia, 2018).

[...] hormônio, eu fiz em casa mesmo, na loucurada. la na farmácia, comprava e aplicava eu mesma [...]. Sem acompanhamento. Sem nenhum acompanhamento! Acho que deu certo. (Jasmim, 2018).

Além de Magnólia e Jasmim, Lírio, Cravo, Sempre-Viva e Hibisco também relatam ter iniciado o uso de hormônios por conta própria. Geralmente, a indicação vem de pessoas próximas ou de grupos das redes sociais, como do Facebook ${ }^{\circledR}$ por exemplo. Lírio e Cravo, que eram acompanhados por uma equipe de saúde da família, afirmam que, como o médico alegava não poder prescrever a hormonioterapia, seguiram orientações de grupos do Facebook ${ }^{\circledR}$, dessa forma, compravam os medicamentos na farmácia. Jasmim afirma: "Hormônio você compra em qualquer farmácia. Uma que ele éliberado, não tem esse negócio de receita. Aí, [vo]cê vai lá e compra".

Lírio e Cravo falam também das fases "pré-T" e "pós-T", como significado de um renascimento, um evento marcante em seu percurso de vida. Apesar desses termos terem sido utilizados somente por eles, a fim de denominar o início do uso do hormônio masculino, observa-se a presença de relatos semelhantes nas demais entrevistas. Os(as) participantes evidenciam a hormonioterapia como um evento marcante, tal como resume Hibisco: "é um ponto assim, um início [...], o primeiro degrau do sonho da gente".

No caso de Sempre-Viva, ela afirma ter iniciado a auto-hormonização aos 24 anos de idade. A sua passabilidade perpassa o uso de hormônios, adquiridos por meio de uma amiga farmacêutica. Porém, apesar de afirmar que seu corpo já possuía algumas características femininas, como "quadril largo", o uso de hormônios foi algo importante para desenvolver e manter sua feminilidade.

Há consequências do uso de hormônio por conta própria para as pessoas transexuais, que podem ser relacionadas com os eventos adversos do uso da medicação. Na possibilidade desses eventos, a internet e as redes sociais representam outra forma de suporte e de informação às pessoas trans.

Outra consequência se refere às modificações corporais advindas do uso de hormônio, que interferem na vida social e nas atividades antes realizadas. Lírio afirma que, quando as características masculinas se pronunciaram, teve que parar de jogar futsal com suas colegas. Para ele: "uma coisa que foi ruim, quando eu comecei a tomar hormônio, foi ter parado de jogar futsal”.

Outro aspecto se refere a não eficácia dos hormônios, como aconteceu com Hibisco que, apesar de ter utilizado bloqueadores de hormônios masculinos por alguns meses, não percebeu mudanças consideráveis na supressão de suas características masculinas. Dessa 
forma, investiu mais no uso de "roupa mais feminina, como as outras mulheres vestem também. [Para] me sentir mais feminina, me sentir mais mulher".

De todos(as) os(as) entrevistados(as), Narciso foi o único que não utilizou hormônios por conta própria, já que teve conhecimento da possibilidade de acompanhamento profissional pelo SUS, por meio da indicação de amigos das redes sociais.

Meu colega, ele me explicou tudo. Eu procurei também na internet. Ele falou assim: [vo]cê tem que pegar um encaminhamento para o endocrinologista. [...]. Meu colega também falou que ele já tinha passado por aqui, e o médico falou que nenhum deles aqui fazia. [...]. Então, eu peguei encaminhamento pra um lá de Belo Horizonte. (Narciso, 2018).

A partir do exposto, o uso de hormônios pelos(as) entrevistados(as) se deu de duas maneiras: auto-hormonização e hormonioterapia. Essas são práticas distintas e que podem, por sua vez, ter impacto diferentes nas pessoas. Auto-hormonização é a prática do uso do hormônio por conta própria, sem acompanhamento de um profissional de saúde ${ }^{15}$, enquanto a hormonioterapia se configura como a prática do tratamento hormonal prescrito e com devido acompanhamento médico ${ }^{10}$.

Pode-se identificar que o uso indiscriminado e sem orientação de um médico sobre o uso de hormônios é um grave problema para a saúde de transexuais. Há reconhecida relação entre o uso de hormônios femininos e a ocorrência de diversas doenças, podendo levar a mortes ou sequelas importantes. Da mesma forma, os homens transexuais, normalmente, realizam a automedicação com doses elevadas de hormônios masculinizantes, se configurando também como um agravante no quadro de saúde dessas pessoas ${ }^{10}$.

As necessidades de saúde de transexuais, incluindo sua identidade e subjetividade, são fatores importantes para o cuidado em saúde, pois a falta de orientação sobre uso de medicamentos pode comprometer a saúde dessas pessoas. Mesmo que se pautem em experiências de outras, que já usam hormônios, o acompanhamento e as orientações por profissionais de saúde são fundamentais ${ }^{10,11,15,21,25-31,33}$.

É importante sinalizar também como o (des)preparo dos serviços de saúde impactam nos IT de transexuais, principalmente, em relação às modificações corporais. $\mathrm{O}$ que chama atenção é que as pessoas, geralmente, buscam e se submetem a diversas formas para realizar os procedimentos de modificações corporais, seja pelo uso de hormônios, seja por métodos cirúrgicos.

Magnólia, além da auto-hormonização, também realizou implante de silicone nos seios e glúteos, fez a depilação a laser dos pelos corporais e implante de "megahair" nos cabelos. Declara que fez "tudo por conta própria, eu nunca ia no médico".

Jasmim, além da auto-hormonização, também partiu para procedimentos cirúrgicos com implante de seios. O que chama atenção são os riscos aos quais se submetem, visto que realizou tais procedimentos a partir de indicação de pessoas do seu ambiente de trabalho. Podemos perceber novamente a influência da rede social na vida de transexuais em seus processos de transição, proporcionada, neste caso, pela profissão.

Mulher sem seios não tem lógica, né? Então, é mais por isso. Procurei e alguém me informou, não lembro muito bem, só sei que eu fui e fiz. É porque eu tinha clientes né, que já faziam. [...] até que, nessa época, não tinha esse tanto de mulher pra colocar seios, pra aumentar, geralmente era mais pra diminuir, né. (Jasmim, 2018).

Sempre-Viva destaca que só não realizou o implante dos seios, devido ao fato de não poder arcar com tal procedimento: "então, eu mesma, eu sou, eu tô louca pra pôr meu peito, [mas] até hoje eu não tive condições, porque é caro”. (Sempre-viva, 2018).

Nesse ponto, as barreiras em relação à realização dos procedimentos parecem se resumir 
às condições financeiras e individuais de cada pessoa, pois conforme afirma Jasmim:

Prótese, [vo]cê tem que procurar um cirurgião, e por aí vai [...]. Até mesmo porque eles focam mais em grana, né? O negócio deles é grana. Os médicos não tão focando [na saúde da gente] mais não... pagou, levou. (Jasmim, 2018).

A necessidade de se reconhecerem fisicamente com o gênero de identificação faz com que alguns(algumas) dos(as) transexuais, além da auto-hormonização, partam para a realização de procedimentos cirúrgicos. No entanto, o que podemos ver é uma lacuna na assistência à saúde dessa população.

\section{O lugar dos serviços de saúde na vida das pessoas transexuais}

Os serviços de saúde, de alguma forma, tangenciam os IT dos(as) transexuais. O PT é realizado no SUS desde a publicação da Portaria $n^{0} 457 / 2008$ pelo MS. Em 19 de novembro de 2013, foi publicada pelo MS a Portaria ${ }^{\circ} 2.803$, em vigor até os dias atuais, a qual redefiniu e ampliou o PT. O texto da Portaria n ${ }^{\circ} 2.803 / 2013$ estabelece idade mínima de 18 anos para procedimentos ambulatoriais, que incluem acompanhamento multiprofissional e hormonioterapia. Para intervenções cirúrgicas, a idade mínima é de 21 anos. A Portaria ${ }^{0}$ 2.803/2013 assegura também uma linha de cuidado, reiterando que a Unidade Básica de Saúde (UBS) deve ser a porta de entrada para o acolhimento com qualidade, reforçando a importância do respeito ao uso do nome social para transexuais ${ }^{28}$.

Até agora, pudemos evidenciar que os serviços de saúde, mesmo que de maneira pontual, perpassaram os processos de identificação, da passabilidade ou transição dos(as) transexuais entrevistados(as). A internet e as redes sociais se apresentaram, na maioria das vezes, como a principal responsável pela indicação desses serviços ou pela realização de procedimentos, demonstrando ocupar um lugar importante no atendimento às suas necessidades.
A busca por esses serviços acompanhou a trajetória de todos(as) os(as) entrevistados(as), visando tanto à compreensão de sua situação de não identificação com o corpo biológico quanto à busca por procedimentos de transição.

No entanto, como eles(as) se depararam com o atendimento prestado no município em que vivem, considerando o PT no SUS?

As experiências com os serviços de saúde são diversas e ocorrem de forma diferente para cada um(a) deles(as). Segundo Magnólia e Lírio, o atendimento recebido nos serviços de saúde do SUS no município em que residem não foi acolhedor, seja em termos do tempo de espera para realizar um procedimento, seja em relação à demanda apresentada sobre redesignação sexual.

Se você vai no posto marcar um exame ou vai marcar um médico especialista, [vo]cê fica na fila dois, três anos. Imagina uma operação dessa que é caríssima? Só faz quem tem dinheiro. Conheço um tanto de travesti que não tem condição de colocar uma prótese, uma prótese com um bom cirurgião [e] por menos de 5 mil reais [vo] cê não faz. (Magnólia, 2018).

Tipo assim, me desmotivou totalmente [...], aqui [no município], eu não fui tratado nem um pouco bem por médico, por psicólogo do SUS, sabe? É, então, me desmotivou totalmente. (Lírio, 2018).

Jasmim afirma ter procurado a Secretaria Municipal de Saúde (SMS) visando "trocar as próteses dos seios". Porém, afirma que está esperando há quase 2 anos uma resposta sobre o encaminhamento para o procedimento.

Liguei pra elas [funcionárias da SMS] e peguei várias coisas da internet falando sobre esse direito nosso, o qual elas nem sabiam. Elas estavam totalmente desinformadas a esse respeito. Aí, que ela ligou pra Belo Horizonte e teve algumas informações e diz que lá [es] tava com um [ambulatório], que [es]tava funcionando. E quando eu cheguei lá, [...] eles falaram que o projeto 
estava em andamento, mas, depois, ele foi cancelado por algum motivo, sei lá, e ficou o dito pelo não dito. Ou seja, não resolveu nada. Não fizeram nada, não me deram posição nenhuma. (Jasmim, 2018).

Parece que o atendimento pelos profissionais de saúde dos diversos serviços extrapola a boa vontade em acolher as pessoas trans, uma vez que, pelos relatos, há um desconhecimento sobre o processo.

O desconhecimento sobre a transexualidade, tanto por parte dos profissionais dos serviços de saúde quanto daqueles que estão na gestão, demonstra como a Rede de Atenção à Saúde (RAS) está (des)organizada e (des) preparada para lidar com as necessidades dos diversos usuários. Somado a isso, há ainda a marginalização das pessoas trans nos serviços de saúde, já que, muitas vezes, o acesso e acolhimento não tem acontecido de maneira adequada $^{32}$. Os indivíduos nem sempre reclamam da falta de conhecimento por parte dos profissionais de saúde, quando do seu atendimento, mas, sim, da "falta de interesse e de responsabilização dos serviços de saúde sobre as suas demandas"33(52). Afinal, trata-se de caminhos que podem ser traçados de forma solitária ou que poderiam ou deveriam ser compartilhados com uma equipe de saúde, que se (co)responsabiliza pelo seu itinerário.

A organização dos serviços públicos de saúde, devido a uma ausência de trabalho em rede, às grandes filas de espera, à falta de acolhimento, entre tantas outras dificuldades, somada à operacionalização dentro de um regime biomédico, que centraliza a intervenção nos procedimentos cirúrgicos, direciona o usuário para os serviços privados de saúde, que oferecem, por custos elevados, uma assistência continuada e acesso aos procedimentos necessários $^{34}$. Dessa forma, a dificuldade no acesso aos serviços de saúde públicos pode ser um fator que os(as) levam buscar formas diversas para o uso de hormônio, ou mesmo as cirurgias de redesignação sexual. Trata-se de uma busca terapêutica diversificada para aliviar suas angústias, uma vez que, ao não encontrar a devida resolutividade nos atendimentos públicos de saúde, ficam à mercê da auto-hormonização e da ação de quaisquer profissionais.

Conforme afirma Magnólia, os seios eram de fundamental importância para seu trabalho: "Na minha profissão, tinha que ter peito". Fez, então, implante de silicone industrial, aplicado por "bombardeiras", porém afirma não ter obtido o resultado esperado. Ela relata que o silicone se "espalhou", algo que, para ela, está relacionado com a sua atitude de não ter feito o repouso necessário após o procedimento. Dessa forma, retirou o silicone e realizou o implante das próteses de seios, que segundo ela, foi " $a$ peça-chave" de sua vida. A partir disso, relata ter buscado uma UBS em Belo Horizonte, que a orientou interromper o uso de hormônios, visto que estava colocando sua vida em risco.

Cravo e Lírio também procuraram pelo serviço de saúde antes de darem início à auto-hormonização. Como não receberam um atendimento resolutivo, resolveram seguir a indicação dos relatos de membros dos grupos do Facebook ${ }^{\circledR}$, e, assim, deram início ao uso dos hormônios por conta própria. A despeito de não terem a prescrição médica para uso dos hormônios, ambos faziam acompanhamento clínico com o médico na UBS em que eram cadastrados e, paralelamente, também consultavam os grupos do Facebook ${ }^{\circledR}$ para comparar os resultados de exames com os demais membros. Posteriormente, ainda sob influência das redes sociais, Cravo e Lírio passaram a ser acompanhados por uma equipe multiprofissional de um hospital de Belo Horizonte, no que tange à prescrição de hormônios.

Narciso, por sua vez, também identificou por meio do Facebook ${ }^{\circledR}$ serviços de saúde destinados a pessoas trans em Belo Horizonte. Dessa forma, iniciou o seu processo de modificação corporal em um ambulatório de uma instituição de pesquisa na capital do estado.

Esses serviços, porém, possuem uma limitação, pois há o acompanhamento em relação ao uso de hormônios, mas os procedimentos cirúrgicos, tão almejado por eles, só é possível 
em serviços privados. Nesse caso, o acesso a esses médicos-cirurgiões também é alvo de discussões na internet e nos grupos das redes sociais, conforme aponta Lírio:

Eu faria minha cirurgia mesmo com o cara lá de Brasília, [...], ele tem um grupo lá, as cirurgias dele ficam perfeitas sabe, mamilo... o método que ele usa, eu faria com esse cara. (Lírio, 2018).

No caso dos três que conseguiram acompanhamento em Belo Horizonte, é importante problematizar como os serviços de saúde têm funcionado. Isso porque, segundo Narciso, o atendimento é realizado em um serviço de saúde no qual a pessoa atendida deve doar dois quilos de alimentos não perecíveis para realizar o acompanhamento médico. Em Minas Gerais, somente um serviço está habilitado e/ou credenciado pelo MS para o $\mathrm{PT}^{35}$. O que chama atenção são as inúmeras possibilidades, reconhecidas ou não pelo MS, que as pessoas trans encontram ao longo das suas trajetórias. Mesmo não havendo o credenciamento dos serviços de Belo Horizonte, a SMS do município onde residem atua, de alguma forma, no acesso a esses serviços, pois propicia aos(às) trans o Tratamento Fora do Domicílio (TFD).

Aí, eu fui lá e conversei na Secretaria se eu poderia ir no ônibus da Secretaria né, pra não pagar pra ir. Aí, a mulher falou que podia, marquei a consulta. E aí, eu faço o tratamento lá. (Lírio, 2018).

De acordo com a Portaria 457/2008, que regulamenta o $\mathrm{PT}$, "os encaminhamentos intermunicipais [...] devem ser feitos com a anuência das respectivas secretarias municipais ou estaduais de saúde" 27(12). Como o município em questão não oferece, em sua rede pública, um fluxo de atendimento às pessoas transexuais, elas são encaminhadas, por meio de veículos da SMS, à capital mineira, que dispõe de serviços de saúde especializados na atenção às pessoas trans. Esse encaminhamento é simbolizado pelo veículo, e não por uma referência de profissionais de saúde que seguem a hierarquização dos serviços no estado. Podemos interpretar que a porta de entrada na RAS do SUS para os(as) transexuais, residentes no município, tem sido a própria SMS no lugar das UBS.

Além do transporte, outra forma de envolvimento da SMS do município é por meio dos pedidos de exames em receituários do SUS. Conforme Narciso, é preciso:

[...] correr atrás, porque lá [em Belo Horizonte] eles me dão o exame. Aí, eu tenho que correr aqui [no município], [para] o médico mudar a folha, pelo SUS pra mim conseguir fazer o exame de graça. (Narciso, 2018).

Diante disso, podemos perceber como a rede para o atendimento à pessoa trans é uma construção individual e parte de um itinerário compartilhado por um grupo de pessoas que tiveram algumas experiências positivas e outras não.

Nesse sentido, Magnólia aponta a importância de ser bem orientada pelas pessoas que vivem situação semelhante, já que seu principal objetivo com a busca de serviços era:

ter conhecimento e uma forma também de abrir caminho pras outras que tão por aí. [...], mas o SUS não faz isso, demora horrores. Quantos miIhões de gente tá na fila? [...] O SUS só investe em coisa barata. (Magnólia, 2018).

Um aspecto importante nos estudos envolvendo IT é o sistema leigo de referência, no qual o sujeito desencadeia uma sequência de práticas destinadas a uma solução terapêuti$\mathrm{ca}^{36}$. Tal sistema pode ser exemplificado pela produção de uma espécie de "saber hereditário", que é passado de geração em geração, pelas "mais antigas" às "mais novinhas"25(5). Ou seja, a experiência compartilhada se torna uma solução para as pessoas em busca de atendimento à saúde. 


\section{Considerações finais}

Este estudo buscou, inicialmente, descrever os caminhos percorridos por pessoas transexuais residentes em um município do interior de Minas Gerais para atendimento às suas demandas e necessidades de saúde. Acreditávamos, em um primeiro momento, que a redesignação sexual era um objetivo importante para elas. Por meio do estudo, foi possível perceber a trajetória percorrida por elas para alcançar não somente as mudanças corporais, mas também superar os conflitos e desafios para se entenderem como uma pessoa trans. Tratou-se, então, de visualizar o que passam as pessoas transexuais, considerando suas vivências, seus conflitos e dificuldades, a partir da sua subjetividade, para conseguirem alcançar sua identidade de gênero. Nesse aspecto, foi possível perceber que o processo de vivência da transexualidade envolve caminhos diversos. Tal processo mostrou-se dinâmico; e, mesmo o estudo tendo abordado alguns (poucos) indivíduos, foi possível perceber que as vivências são compartilhadas entre as pessoas trans de forma coletiva. Trata-se de uma condição que parece não ser vista ainda por profissionais de saúde e gestores da RAS, bem como por parte de pessoas do convívio social.

Quando inserimos este estudo em uma discussão sobre a Reforma Sanitária, e pensamos sobre os princípios norteadores do SUS, tais como a universalidade e a integralidade, podemos perceber como as demandas e necessidades de saúde das pessoas trans têm sido respondidas pelos diversos profissionais envolvidos na RAS. Percebemos que elas têm buscado acesso nos serviços de saúde do SUS, mas se deparam com inúmeros obstáculos, que mais as afastam do que as aproximam das instituições de saúde ${ }^{32}$. Talvez, por isso, busquem as redes sociais como forma de encontrar apoio em outras pessoas que as auxiliarão a compreender e a expressar sua transexualidade.
Isso sinaliza para a importância deste estudo em, pelo menos, três aspectos: social, político e de saúde. Todos esses aspectos estão inter-relacionados e devem ser vistos como possibilidade de reflexão, principalmente para as pessoas que se interessam pelo tema e/ou residem em localidades onde falar em transexualidade é dizer algo estranho ou novo. A partir dos IT das pessoas transexuais entrevistadas, foi possível refletir sobre como questões relacionadas com heteronormatividade e binarismo de gênero podem impactar na vida de pessoas, que não se identificam com o que se é socialmente definido como homem e mulher, repercutindo em práticas discriminatórias por parte da família e dos amigos. Do aspecto político, mostra-nos a necessidade de nos posicionarmos politicamente contra a discriminação e a exclusão da população LGBT, naturalizando a discussão e permitindo que as pessoas conheçam sobre os caminhos pelos quais passam essas pessoas a fim de alcançarem sua identidade de gênero. Em termos de saúde, tratou-se de uma denúncia sobre o nosso sistema de saúde, visto que nos fez questionar sobre como o sistema de saúde público tem respondido às demandas dessas pessoas. Nesse caso, não se trata de destacar somente as pessoas trans, pois, antes de estarem nessa condição, são pessoas que possuem demandas e necessidades de saúde como qualquer outro sujeito.

\section{Colaboradores}

Hanauer OFD (0000-0002-4519-2101)* realizou a coleta, análise e discussão dos dados, revisão da literatura sobre o tema e objeto do estudo e organizou a versão inicial e final do manuscrito. Hemmi APA (0000-0003-35139523)* contribuiu para a orientação da revisão de literatura, para o trabalho de campo e para a escrita do manuscrito. 


\section{Referências}

1. Brasil. Ministério da Saúde. Campanha Cuidar bem da saúde de cada um, faz bem pra todos, faz bem pra o Brasil. Cartilha LGBT - Saúde Trans. [acesso em 2018 ago 12]. 2016. Disponível em: http://portalarquivos2.saude.gov.br/images/pdf/2016/fevereiro/18/ CARTILHA-Equidade-10x15cm.pdf.

2. Valadares C. Ministério da Saúde habilita novos serviços ambulatoriais para Processo Transexualizador [internet]. [acesso em 2017 nov 7]. Disponível em: http://www.saude.mg.gov.br/component/gmg/ story/8923-ministerio-da-saude-habilita-novos-servicos-ambulatoriais-para-processo-transexualizador.

3. Teixeira AM, Morais FJSN, Teixeira MPM. Transexualidade e travestilidade na saúde. In: Brasil. Ministério da Saúde. Transexualidade e travestilidade na saúde. Brasília, DF: Ministério da Saúde; 2015.

4. Simpson K. Transexualidade e travestilidade na saúde. In: Brasil. Ministério da Saúde. Transexualidade e travestilidade na saúde. Brasília, DF: Ministério da Saúde; 2015.

5. Bento B. A reinvenção do corpo: sexualidade e gênero na experiência transexual. Rio de Janeiro: Garamond; 2006.

6. Borrillo D. Homofobia: história e crítica de um preconceito. Belo Horizonte: Autêntica; 2010.

7. Pinho PA, Pereira PPG. Itinerários terapêuticos: trajetórias entrecruzadas na busca por cuidados. Interface. $2012 ; 16(41): 435-450$.

8. Godoy AS. Introdução à pesquisa qualitativa e suas possibilidades. Rev. Adm empr. 1995; 35(2):57-63.

9. Gerhardt TE. Itinerários terapêuticos e suas múltiplas dimensões: desafios para a prática da integralidade e do cuidado como valor. In: Roseni P, Mattos RA, organizadores. Razões públicas para a integralidade em saúde: o cuidado como valor. Rio de Janeiro: IMS; UERJ; CEPESC; ABRASCO; 2007. p. 279-300. (v. 1).
10. Brasil. Ministério da Saúde. Política Nacional de Saúde Integral de Lésbicas, Gays, Bissexuais, Travestis e Transexuais. Brasília: Ministério da Saúde, 2013. [acesso em 2017 nov 17]. Disponível em: http://bvsms.saude.gov.br/bvs/publicacoes/politica_nacional saude_lesbicas_gays.pdf.

11. Rodrigues FD. (Des)caminhos em busca de cuidado: uma análise da rede de assistência à saúde para pessoas transexuais e travestis em Juiz de Fora/MG [tese]. Juiz de Fora: Universidade Federal de Juiz de Fora; 2018.269 p.

12. Conselho Nacional de Saúde. Resolução n 466 , de 12 de dezembro de 2012. [acesso em 2018 jan 8]. Disponível em: http://bvsms.saude.gov.br/bvs/saudelegis/ cns/2013/res0466_12_12_2012.html.

13. Lima NC, Baptista TWF, Vargas EP. Ensaio sobre 'cegueiras': itinerário terapêutico e barreiras de acesso em assistência oftalmológica. Interface. 2017; 21(62):615-627.

14. Bonassi BC. Cisnorma: Acordos societários sobre o sexo binário e cisgênero. Dissertação (mestrado) Universidade Federal de Santa Catarina, Centro de Filosofia e Ciências Humanas, Programa de Pós-Graduação em Psicologia, Florianópolis; 2017.

15. Almeida AS. Vidas em espera: uma etnografia sobre a experiência do tempo no processo transexualizador [dissertação]. Goiânia: Universidade Federal de Goiás; 2018. 148 p.

16. Butler J. Problemas de gênero: feminismo e subversão da identidade. 8. ed. Rio de Janeiro: Civilização Brasileira; 2015.

17. Lionço T. Atenção integral à saúde e diversidade sexual no Processo Transexualizador do SUS: avanços, impasses, desafios. Physis. 2009; 19(1):43-63.

18. Conselho Nacional de Justiça. Provimento $n^{0} 73$, de 28 de junho de 2018. [acesso em 2019 ago 10]. 
Disponível em: https://www.cnj.jus.br/busca-atos-adm?documento=3503.

19. Gianna MC. Ambulatório de saúde integral para travestis e transexuais: cinco anos de desafios e realizações. In: Brasil. Ministério da Saúde. Transexualidade e travestilidade na saúde. Brasília, DF: Ministério da Saúde; 2015 .

20. Moreira MA, Gomes AJM. Social representations students graduating in Nursing about transsexuality. Revista de enfermagem. UFPE [internet]. 2013. [acesso em 2018 fev 21]. Disponível em: https://periodicos.ufpe.br/revistas/revistaenfermagem/article/viewFile/11677/13856.

21. Souza MHT, Signorelli MC, Coviello, DM, et al. Itinerários terapêuticos de travestis da região central do Rio Grande do Sul, Brasil. Ciênc. Saúde Colet. 2014; 19(7):2277-2286.

22. Martins PV, Iriart JAB. Itinerários terapêuticos de pacientes com diagnóstico de hanseníase em Salvador, Bahia. Physis. 2014; 24(1):273-289.

23. Santos CGP. Saúde?! Completo bem-estar psicossocial de um indivíduo: tudo que uma pessoa trans não possui. In: Brasil. Ministério da Saúde. Transexualidade e travestilidade na saúde. Brasília, DF: Ministério da Saúde; 2015.

24. Wittmann I. Corpo, gênero e identidade: Experiências transgênero na cidade de Manaus [dissertação]. Manaus: Universidade Federal do Amazonas; 2016. $153 \mathrm{p}$.

25. Leite AFS, Santos C. Tecnologias de gênero e magia: hormonioterapia e as experiências de vida de mulheres trans. Ex aequo, Lisboa, n. 38, p.83-94, dez. 2018. [acesso em 2019 mar 14]. Disponível em: http://www.scielo.mec.pt/scielo.php?script=sci arttext\&pid=S0874-55602018000200007\&lng=pt\& nrm=iso.

26. Brasil. Ministério da Saúde. Portaria ${ }^{\circ} 1707$, de 18 de agosto de 2008. Institui, no âmbito do Sistema Úni- co de Saúde (SUS), o Processo Transexualizador, a ser implantado nas unidades federadas, respeitadas as competências das três esferas de gestão (Revogada pela PRT GM/MS no 2803 de 19.11.2013). [acesso em 2017 dez 8]. Disponível em: http://bvsms.saude.gov. br/bvs/saudelegis/gm/2008/prt1707_18_08_2008. html.

27. Brasil. Ministério da Saúde. Portaria n ${ }^{\circ} 457$, de 19 de novembro de 2008. [acesso em 2017 dez 8]. Disponível em: http://bvsms.saude.gov.br/bvs/saudelegis/ gm/2013/prt2803_19_11_2013.html.

28. Brasil. Ministério da Saúde. Portaria $\mathrm{n}^{\circ} 2.803$, de 19 de novembro de 2013. Redefine e amplia o Processo Transexualizador no Sistema Único de Saúde (SUS). [acesso em 2017 dez 8]. Disponível em: http://bvsms.saude.gov.br/bvs/saudelegis/gm/2013/ prt2803_19_11_2013.html.

29. Brasil. Ministério da Saúde. Transexualidade e travestilidade na saúde. Brasília, DF: Ministério da Saúde; 2015.

30. Conselho Nacional de Saúde. Resolução $n^{\circ} 510$, de 07 de abril de 2016. [acesso em 2018 maio 11]. Disponível em: http://conselho.saude.gov.br/resolucoes/2016/reso510.pdf.

31. Oliveira MJ. Uma etnografia sobre o atendimento psicoterapêutico a transexuais Estudos Feministas. 2014 [acesso em 2018 ago 2]; 22(3). Disponível em: https://periodicos.ufsc.br/index.php/ref/article/ viewFile/36749/28570.

32. Rocon PC, Rodrigues A, Zamboni J, et al. Dificuldades vividas por pessoas trans no acesso ao Sistema Único de Saúde. Ciênc. Saúde Colet. 2016; 21(8): 25172526.

33. Franco TB, Merhy EE. Trabalho, produção do cuidado e subjetividade em saúde: textos reunidos. São Paulo: Hucitec; 2013

34. Lima F, Cruz KT. Os processos de hormonização e a produção do cuidado em saúde na transexualidade 
masculina. Sex., Salud Soc. 2016 [acesso em 2019 mar 14]; (23):162-186. Disponível em: http://www.scielo. br/scielo.php?script=sci_arttext\&pid=S1984648720 $16000200162 \& \operatorname{lng}=$ en $\&$ nrm $=$ iso.

35. Brasil. Ministério da Saúde. Portal MS: gays, lésbicas, bissexuais, travestis e transexuais.2017. [acesso 2018 ago 18]. Disponível em: http://portalms.saude. gov.br/component/content/article/41380-gays-lesbicas-bissexuais-travestis-e-transexuais.
36. Alves PC. A experiência da enfermidade: considerações teóricas. Cad. Saúde Pública. 1993 [acesso em 2018 ago 29]; 9(3):263-271. Disponível em: http://www. scielo.br/scielo.php?script=sci_arttext\&pid=S0102$-311 X 1993000300014 \& \operatorname{lng}=\mathrm{en} \& \mathrm{nrm}=\mathrm{iso}$.

Recebido em 09/06/2019

Aprovado em 25/08/2019

Conflito de interesses: inexistente

Suporte financeiro: Conselho Nacional de Desenvolvimento

Científico e Tecnológico (CNPq) - Edital 01/2016 